\title{
Observatório de Direito Público
}

\author{
Alberto R. Gonzales, Procurador Geral e outros v. Centro \\ Espírita Beneficente União do Vegetal e outros ${ }^{\dagger}{ }^{1}$
}

\section{Resumo}

Tradução do acórdão da Suprema Corte dos Estados Unidos envolvendo a liberação do chá "hoasca". Tal decisão é considerada a mais importante do último século envolvendo a liberdade religiosa nos Estados Unidos, pois excepciona o uso de uma substância proibida pela Convenção da ONU sobre Substâncias Psicotrópicas em favor do exercício sincero da religião.

Palavras-chave

Suprema Corte; Liberdade de Religião; Chá "Hoasca".

\section{Alberto R. Gonzales, Attorney General, et al., v. O Centro Espirita Beneficente Uniao do Vegetal et al.}

\author{
Abstract \\ sincere exercise of religion. \\ Keywords \\ Supreme Court; Freedom of religion; "Hoasca” Tea.
}

Translation of the judgment of the Supreme Court of the United States involving the liberation of "hoasca" tea. Such a decision is considered to be the most important decision of the last century involving religious freedom in the United States, since it excludes the use of a substance prohibited by the UN Convention on Psychotropic Substances in favor of the

+ [N.T.] O texto foi originalmente publicado em língua inglesa e foi traduzido para a língua portuguesa por André Fagundes, Mestre em Direito Público pela Universidade de Coimbra. E-mail: andre_fagundes1@yahoo.com.br. Revisado por Evandra Maria Grenier Fagundes.

1 Ordem de Remessa [certiorari] ao Tribunal Regional Federal da Décima Região N. 04-1084. Discutido em 1 o de novembro de 2005. Decidido em 21 de fevereiro de 2006.Também denominado writ ofcertiorari, este termo não possui equivalente no sistema jurídico brasileiro. Basicamente, é um pedido à Suprema Corte dos Estados Unidos para que a causa seja apreciada. Para os casos que decide julgar, a Suprema Corte expede uma ordem de remessa dos autos (writ of certiorari) para as instâncias inferiores. [N. do T.] 


\section{Relatório}

O Congresso promulgou a Lei de Restauração da Liberdade Religiosa [Religious Freedom Restoration Act - RFRA] em 1993, em resposta ao julgamento do caso Divisão de Emprego do Departamento de Recursos Humanos de Oregonv. Smith, 494 U.S. 872, onde, ao confirmar que uma lei de aplicabilidade geral restringia o uso sacramental de peiote, esta Corte considerou que a Cláusula de Livre Exercício Religioso da Primeira Emenda não exige que os juízes se dediquem a uma avaliação caso a caso das restrições religiosas impostaspor leis visivelmente constitucionais, Id., n. 883-890. Entre outras coisas, a RFRA proíbe o Governo Federal de restringir substancialmente o exercício religioso de uma pessoa, "ainda que a restrição resulte de uma norma de aplicabilidade geral", 42 U.S.C. $\$ 2000 b b-1(a)$, exceto quando o Governo possa "demonstrar que a aplicação da restrição à pessoa (1) promove um interesse público relevante; e (2) é o meio menos restritivo para promover esse interesse", §2000bb-1(b).

Os membros da igreja inquirida (UDV) recebem a comunhão bebendo hoasca, um chá feito de plantas origináriasda Floresta Amazônica que contém DMT, um alucinógeno regulado pela Lista I da Lei de Substâncias Controladas [Controlled Substances Act], ver 21 U.S.C.§812(c), Lista I(c). Depois que os agentes aduaneiros dos EUA apreenderam uma remessa de hoasca na sede americana da UDV e ameaçaram processá-la, a UDV ajuizou a presente ação requerendo a concessão de tutela declaratória e mandamental, alegando, inter alia, que a aplicação da Lei de Substâncias Controladas ao uso sacramental da hoasca da UDV viola a RFRA. Em uma audiência sobre o pedido da UDV de concessãodeliminar, o Governo admitiu que o pedido em causa restringiria substancialmente o exercício sincero da religião, mas argumentou que a limitação em análise não violava a RFRA porque a aplicação da Lei de Substâncias Controladas era o meio menos restritivo para promover três interesses públicos relevantes: proteger a saúde e a segurança dos membros da UDV; impedir o desvio da hoasca do contexto religioso para o uso recreativo, e cumprir a Convenção das Nações Unidas sobre Substâncias Psicotrópicas de 1971. O Juízo Federal de 1a. Instância concedeu a tutela, concluindo que, como as provas das partes sobre os riscos para a saúde e o desvio eram igualmente equilibradas, o Governo não havia demonstrado um interesse convincente que justificasse a restrição substancial para a UDV. Considerou, também, que a Convenção de 1971 não se aplica à hoasca. O Tribunal Regional Federal da 10a Região manteve a decisão.

Decisão: Os Tribunais a quo não erraram ao decidir que o Governo não demonstrou, em sedede liminar, um interesse relevante em proibir o uso sacramental da hoasca pela UDV. Pp. 619. 
1. Esta Corte rejeita o argumento do Governo segundo o qual o equilíbrio probatório quanto aos possíveis danos e desvios é uma base insuficiente para a concessão de uma medida liminar contra a aplicação da Lei de Substâncias Controladas. Considerando que o Governo reconheceu perante o Juízo Federal de 1ạ Instância que a UDV tem um prima facie case ${ }^{2}$ com base na RFRA, e que as provas são equivalentes em relação à defesa indireta de mérito sobre a qual o Governo suportou o ônus da prova, a UDV demonstrou efetivamente a probabilidade de êxito nomérito. O argumento do Governo segundo o qual, embora suportasse o ônus de demonstrar um interesse imperiosodurante o julgamento de mérito, a UDV deveria ter suportado o ônus de refutar tais interesses na audiência preliminar, é afastado em Ashcroft v. American Civil Liberties Union, 542 US 656, 666. Nestecaso, ao manter a concessão de uma medida liminar contra o Governo, esta Corte argumentou que os ônus relativos ao teste de interesse imperioso em sede de liminar seguem os ônus do julgamento. A tentativa do Governo de limitar a regra de Ashcroft às restrições de conteúdo à liberdade de expressão é ineficaz. O fato de que Ashcroft envolveu tal restrição não afetou de forma alguma a avaliação da Corte sobre as consequências de ter o ônus do julgamento para fins de concessão de liminar. A decisão expressa do Congresso de estabelecer o teste de interesse imperioso indica que as impugnações da RFRA devem ser julgadas da mesma maneira que os pedidos constitucionalmente exigidos pelo teste, inclusive em sede deliminar. Pp. 6-8.

2. Também é rejeitada a alegação central do Governo de que, por ter um interesse imperioso na aplicação uniforme da Lei de Substâncias Controladas, nenhuma exceção à proibição do DMT pode ser feita para autorizar a UDV. O Governo argumenta, inter alia, que a descrição das substâncias da Lista I da Lei como tendo "um alto potencial de abuso", "nenhum uso médico atualmente aceito" e a "falta de segurança aceita para uso... sob a supervisão médica", 21 U.S.C. §812(b)(1), por si só, exclui qualquer consideração de exceções individualizadas, e que o sistema regulatório "fechado" da Lei, que proíbe qualquer uso de substâncias controladas, exceto quando autorizadpela própria Lei, ver Gonzales v. Raich, 545 US não pode funcionar corretamente se estiver sujeito a isenções judiciais. Pp. 8-16.

(a) A Lei de Restauração da Liberdade Religiosa e seu teste de escrutínio rigoroso [strict scrutiny test $]^{3}$ contemplam uma investigação mais centrada do que a abordagem categórica do

\footnotetext{
2 Segundo o Oxford Dictionary of Law, primafacie case é um caso que tenha sido instruído com prova suficiente para que seja considerado como comprovado, caso não haja prova razoável em contrário. Jonathan Law (Editor).Oxford: Oxford University Press, 8. ed. 2015. p. 477. [N. do T.]

${ }^{3}$ Semelhante à metódica da proporcionalidade, strict scrutiny é uma técnica empregada pela Suprema Corte dos EUA para o controle de constitucionalidade. Segundo esse critério, um ato só será considerado constitucional caso seja: a) justificado por um interesse governamental convincente; b) estreitamente adequado às suas finalidades, e seja o meio menos restritivo para alcançar seu objetivo. [N. do T.]
}

Revista Publicum 
Governo. A RFRA exige que o Governo demonstre que o teste de interesse imperiososeja condizente com a aplicação da lei contestada "para a pessoa" - o requerente em questão, cujo exercício sincero da religião esteja sendo substancialmente restringido. 42 U.S.C. §2000bb-1(b). 0 artigo $2000 \mathrm{bb}(\mathrm{b})(1)$ adotou expressamente o teste de interesse imperioso em Sherbert v. Verner, 374 US 398 e em Wisconsin v. Yoder, 406 US 205. Neste caso, o Tribunal examinou além dos interesses amplamente formulados que justificam a aplicabilidade geral das diretrizes governamentais, analisou minunciosamente os danos alegados e concedeu exceções específicas a determinados requerentes religiosos. Id., em 213, 221, 236; Sherbert, supra, em 410. Além do âmbito de livre exercício da religião, o Tribunal observou que o "contexto é importante" na aplicação do teste de interesse imperioso, Grutter v. Bollinger, 539 US 306, 327, e enfatizou que o objetivo fundamental do escrutínio rigoroso é levar em consideração as "diferenças relevantes", Adar and Constructors, Inc. v. Peña, 515 US 200, 228. Pp. 9-10.

(b) No âmbito da investigação mais centrada exigida pela Lei de Restauração da Liberdade Religiosa, a mera invocação do Governo às características gerais das substâncias da Lista I não pode prevalecer. Embora as substâncias da Lista I, como o DMT, sejam excepcionalmente perigosas, ver, por exemplo, Touby v. Estados Unidos, 500 U.S. 160, 162, não há nenhuma indicação de que o Congresso, ao classificar o DMT, tenha considerado os danos causados pelo uso específico em análise. Essa questão foi discutida abaixo. Antes queo Juízo Federal de 1ạ Instância considerasse que o Governo não havia suportado o ônus de demonstrar um interesse imperioso na prevenção de tais danos, o Tribunal observou que não poderia ignorar a classificação e as decisões do Congresso. Mas a deliberação do Congresso de que o DMT deve estar incluído na Lista I, por si só, não fornece uma resposta categórica que desobrigue o Governo de suportar o ônus imposto pela Lei de Restauração da Liberdade Religiosa. A autorização da Lei de Substâncias Controladas ao Procurador Geral para "dispensar o requisito de registro de certos fabricantes, distribuidores ou prescritores se ele o considerar compatível com a saúde pública e a segurança", 21 U.S.C.§822(d), reforça que as deliberaçõe sdo Congresso em relação às substâncias da Lista I não devem serofator determinante, para fins de RFRA, que o Governo atribuiria a eles. Na verdade, apesar do fato de que tudo o que o Governo diz sobre o DMT na hoasca se aplica em igual medida à mescalina no peiote, outra substância da Lista I, tanto o Executivo quanto o Congresso estabeleceram uma exceção na Lei de Substâncias Controladas para o uso religioso do peiote pelo povo indígena americano - ver 21 CFR §1307.31; 42 U.S.C. $\$ 1996 a(b)(1)$. Se tal uso é permitido em face das decisões gerais do Congresso para centenas de milhares de índios americanos praticando sua fé, essas mesmas determinações, por si só, não podem impedir a concessão de uma exceção semelhante para os cerca de 130 membros americanos da UDV que desejam praticar a suafé. Ver Igreja de Lukumi Babalu Aye,

Revista Publicum

Rio de Janeiro, v.4, n.1, 2018, p. 323-341

http://www.e-publicacoes.uerj.br/index.php/publicum

DOI: https://doi.org/10.12957/publicum.2018.33892 
Inc. v. Hialeah, 508 U.S.520,547. O argumento do Governo segundo o qual a existência de uma isenção criada pelo Congresso para o uso do peiote não indica que a Lei das Substâncias Controladas seja passível de exceções criadas judicialmente é equivocado, na medida em que a RFRA estabelece claramente que o judiciário deve reconhecer exceções, ver $§ 2000 b b-1(c)$. Pp. 11-13.

(c) A exceção para o uso do peiote também enfraquece fatalmente a alegação mais ampla do Governo de que a Lei de Substâncias Controladas estabelece um sistema regulatório fechado, que não admite exceções previstas na Lei de Restauração da Liberdade Religiosa. A exceção para o uso do peiote está em vigor desde a edição da Lei das Substâncias Controladas, e não há provas de que tenha reduzido a capacidade do Governo de impor a proibição do seu uso por não índios. A referência do Governo aos casos pré-Smith, que afirmama necessidade de uniformidade na rejeição dos pedidos de isenções religiosas com basena Cláusula de Livre Exercício, é ineficaz. Esses casos não abrangiam a noção de que um interesse geral na uniformidade justificava um ônus substancial sobre o exercício religioso, mas ao invés disso, examinavam a necessidade alegada e explicavam porque as isenções negadas não poderiam ser acolhidas. Ver, por exemplo, Estados Unidos v. Lee, 455 U.S. 252, 258, 260. Eles demonstram que o Governo pode apresentar um interesse convincente na aplicação uniforme de um determinado programa, oferecendo provas de que o acolhimento das isenções religiosas requeridas comprometeria seriamente sua capacidade de administrar o programa. Aqui, o argumento do Governo sobre uniformidade não se baseia tanto no programa institucional em questão quanto nas preocupações de piso escorregadio [slippery-slope] ${ }^{4}$, que poderiam ser invocadas em resposta a qualquer pedido de exceção com base na RFRA a uma lei de aplicabilidade geral, isto é, "se eu abrir uma exceção para você, eu vou ter que abrir para todos, então não há exceções". Mas a Lei de Restauração da Liberdade Religiosa opera exigindo a consideração, de acordo com o teste de interesse convincente, das exceções à[s]"normas[s] de aplicabilidade geral". §2000bb-1(a). A decisão do Congresso de que o teste previsto na leié "eficaz... para encontrar equilíbrios razoáveis entre a liberdade religiosa e os mais importantes interesses públicos concorrentes", §200bb(a)(5), encontra respaldo em Sherbert, supra, em 407, e Cutter v. Wilkinson, 544U.S. Embora haja casos em que uma necessidade de uniformidade impeça o reconhecimento de exceções às leis genericamente aplicáveis ao abrigo da RFRA, seria surpreendente achar que este fosse tal caso, dada a isenção de longa data do uso do peiote e o fato de que a verdadeira razão pela qual o Congresso promulgou a RFRA foi responder a uma decisão que negou um direito reivindicado

\footnotetext{
${ }^{4}$ Segundo o Cambrigde Dictionary, slippery-slope é uma situação ou hábito ruim que, após ter começado, provavelmente irá ficar pior. Disponível em: <https://dictionary.cambridge.org/pt/dicionario/ingles/slippery-slope>. Acesso em 25 mar. 2018. [N. do T.]

Revista Publicum

Rio de Janeiro, v.4, n.1, 2018, p. 323-341

http://www.e-publicacoes.uerj.br/index.php/publicum

DOI: https://doi.org/10.12957/publicum.2018.33892
} 
ao uso sacramental de uma substância controlada. O Governo não demonstrou que a concessão de uma isenção à UDV causaria um tipo de prejuízo administrativo considerado como um interesse imperioso, conforme demonstrado, por exemplo, em Lee. Não pode agora querer compensar o seu fracasso em convencer o Juízo Federal quanto às suas preocupações com a saúde ou com o desviosob o ousado argumento de que não pode haver, de maneira nenhuma, exceções à Lei de Substâncias Controladas com base na RFRA. Pp. 13-16.

3. O Governo argumenta de forma não persuasiva que tem um interesse legítimo no cumprimento da Convenção das Nações Unidas de 1971. Embora esta Corte não concorde com o Juízo Federal de 1a Instância de que a Convenção não abrange a hoasca, isso não significa, automaticamente, que o Governo tenha demonstrado um interesse convincente na aplicação da Lei de Substâncias Controladas, que implementa a Convenção, quanto ao uso sacramental pela UDV. Nesta fase, basta que o Governo não tenha apresentado nenhuma prova quanto às consequências internacionais de se conceder uma isenção à UDV, mas simplesmente se baseou em dois depoimentos juramentados de funcionários do Departamento de Estado atestando a importância geral (e indubitável) de honrar as obrigações internacionais e manter a liderança dos Estados Unidos na guerra internacional contra as drogas. No âmbito da RFRA, a invocação de tais interesses gerais, por si só, não é suficiente. Pp. 16-18.

389 F. 3d 973, confirmado e remetido.

ROBERTS, Presidente da Suprema Corte, proferiu o voto, em que todos os demais membros da Corte acompanharam, exceto ALITO, J., que não participou da discussão e da decisão do caso.

\title{
Suprema Corte dos Estados Unidos
}

\section{Alberto R. Gonzales, Procurador Geral e outros recorrentes v. Centro Espírita Beneficente União do Vegetal e outros}

\author{
Writ of certiorari ao Tribunal Regional Federal da Décima \\ Região [21 de fevereiro de 2006] \\ O Presidente da Suprema Corte ROBERTS relatou o acórdão.
}


Uma seita religiosa com origens na Floresta Amazônica recebe comunhão bebendo um chá sacramental, feito de plantas originárias da região, que contém um alucinógeno regulado pelo Governo Federal através da Lei de Substâncias Controladas. O Governo admite que esta prática seja um exercício sincero da religião, mas, apesar disso, tentou proibir a pequena filial americana da seita de se envolver na prática, sob o argumento de que a Lei das Substâncias Controladas impede o uso do alucinógeno. A seita ingressou com uma ação judicial para impedir a aplicação da proibição do uso sacramental do chá e requereu uma medida liminar.

Baseou-se na Lei de Restauração da Liberdade Religiosa de 1993, que proíbe o Governo Federal de sobrecarregar substancialmente o exercício religioso de uma pessoa, a menos que o Governo "demonstre que a aplicação do ônus à pessoa" representa o meio menos restritivo para promover um interesse imperioso. 42 U.S.C. $\$ 2000 b b-1(b)$. O Juízo Federal concedeu a medida liminar, a qual foi confirmada pelo Tribunal Regional Federal. Admitimos o pedido do Governo para aremessa dos autos à Suprema Corte. Diante desta Corte, a alegação central do Governo é de ter um interesse imperioso na aplicação uniforme da Lei de Substâncias Controladas, de modo que nenhuma exceção à proibição de uso do alucinógeno pode ser feita para acomodar a prática religiosa sincera da seita. Concluímos que o Governo não se desincumbiu do ônus expressamente imposto pelo Congresso na Lei de Restauração da Liberdade Religiosa e mantemos a concessão da medida liminar.

I

No caso Divisão de Emprego do Departamento de Recursos Humanos de Oregon v. Smith, 494 U.S. 872 (1990), esta Corte considerou que a Cláusula de Livre Exercício Religioso da Primeira Emenda não proíbe os governos de restringir práticas religiosas por meio de leis de aplicação geral. Em Smith, rejeitamos uma impugnação a uma lei de Oregon que negou benefícios de seguro-desemprego para usuários de drogas, incluindo os povos nativos americanos envolvidos no uso sacramental de peiote. Id., em 890. Ao fazê-lo, rejeitamos a interpretação da Cláusula de Livre Exercício Religioso apresentadano caso Sherbert v. Verner, 374 US 398 (1963) e, de acordo com casos anteriores, ver Smith, 494 US, em 879-880, 884-885, consideramos que a Constituição não exige que os juízes façam uma avaliação caso a caso das restrições religiosas impostas pelas leis visivelmente constitucionais. Id., em 883-890.

O Congresso respondeu através da promulgação da Lei de Restauração da Liberdade Religiosa de 1993 (RFRA), 107 Stat. 1488, tal como alterada, 42 U.S.C. §2000bb et seq., que adota uma disposição legal comparável à norma constitucional rejeitada em Smith. De acordo com a RFRA, o Governo Federal não pode, como matéria legal, restringir significativamente o exercício da religião de uma pessoa, "mesmo que a restrição resulte de uma norma de aplicabilidade 
geral". §2000bb-1(a). A única exceção previstaem lei exige que o Governo satisfaça o teste de interesse imperioso - "para demonstrar que a aplicação da restrição à pessoa - (1) é favorável a um interesse público relevante; e (2) é o meio menos restritivo para promover esse interesse público imperioso." §2000bb-1(b). Uma pessoa cujas práticas religiosas sejam restringidas, em violação à RFRA, "pode alegar tal violação como forma de pedido ou defesa em um processo judicial e obter um provimento jurisdicional adequado". $§ 2000 b b-1(c) .^{5}$

A Lei das Substâncias Controladas, 84 Stat. 1242, com as alterações introduzidas, 21 U.S.C. \$801 et seq. (2000 ed. e Supp. I), regula a importação, fabricação, distribuição e uso de substâncias psicotrópicas. A lei divide as substâncias em cinco listas com base no seu potencial de abuso, no uso médico aceito e na sua segurança. Ver §812(b) (2000 ed.). As substâncias relacionadas na Lista I da Lei estão sujeitas às restrições mais abrangentes, incluindo uma proibição expressa de toda importação e uso, exceto no âmbito de projetos de pesquisa estritamente regulamentados. Ver $\S \S 823,960(a)(1)$. A Lei autoriza a imposição de uma pena criminal pela simples posse das substâncias da Lista I, ver $§ 844(a)$, e impõe uma pena criminal pela posse "com a intenção de fabricar, distribuir ou ministrar" tais substâncias, ver $§ \S 841(a),(b)$.

O Centro Espírita Beneficente União do Vegetal (UDV) é uma seita espírita cristã no Brasil, com uma filial americana de aproximadamente 130 indivíduos. O fundamental na crença da UDV é receber a comunhão através da hoasca (pronunciado "wass-ca"), um chá sacramental feito de duas plantas originárias da região amazônica. Uma das plantas, a psicotriaviridis, contém dimetiltriptamina (DMT), um alucinógeno cujos efeitos são reforçados por alcaloides da outra planta, banisteriopsiscaapi. O DMT, bem como "qualquer material, composto, mistura ou preparação, que contenha qualquer quantidade de [DMT]", está relacionado na Lista I da Lei de Substâncias Controladas. $§ 812$ (c), Anexo I (c).

Em 1999, inspetores da alfândega dos Estados Unidos interceptaram uma remessa destinada à UDV americana contendo três recipientes de hoasca. Uma investigação posterior revelou que a UDV já havia recebido 14 remessas de hoasca. Os inspetores então apreenderam a remessa interceptada e ameaçaramprocessar criminalmente a UDV.

A UDV ingressou com uma ação judicial em face do Procurador-Geral e outros funcionários federais responsáveis pela aplicação da lei, requerendo a concessão de tutela declaratória e mandamental. Na petição inicial alegou, inter alia, que a aplicação da Lei de Substâncias Controladas ao uso sacramental da hoascapela UDV viola a RFRA. Antes do

\footnotetext{
${ }^{5}$ Conforme originalmente promulgada, a RFRA aplicou tanto aos Estados quanto ao Governo Federal. No caso City of Boerne v. Flores, 521 U.S. 507 (1997), mantivemos o pedido aos Estados para além da autoridade legislativa do Congresso, consoante o disposto no §5음 da 14a Emenda.
}

Revista Publicum

Rio de Janeiro, v.4, n.1, 2018, p. 323-341

http://www.e-publicacoes.uerj.br/index.php/publicum

DOI: https://doi.org/10.12957/publicum.2018.33892 
julgamento, a UDV requereu uma medida liminar, para que pudesse continuar a praticar sua fé enquanto estivesse aguardando o julgamento do mérito.

$\mathrm{Na}$ audiência sobre a medida liminar, o Governo admitiu que a aplicação da Lei de Substâncias Controladas restringiria substancialmente o exercício sincero da religião pela UDV. Ver Centro Espírita Beneficente União do Vegetal v.Ashcroft, 282 F. Supp. 2d 1236, 1252 (NM 2002). O Governo argumentou, no entanto, que essalimitação não violava a RFRA, porque a aplicação da Lei de Substâncias Controladas neste caso era o meio menos restritivo para promover três interesses públicos relevantes: proteger a saúde e segurança dos membros da UDV; evitar o desvio da hoasca do contexto religioso para o uso recreativo, e cumprir a Convenção das Nações Unidas sobre Substâncias Psicotrópicas de 1971, um tratado assinado pelos Estados Unidos e implementado pela Leide 21 de fevereiro de 1971, [1979-1980], 32 U.S.T. 543, T.I.A.S. n. 9725 . Ver 282 F. Supp. 2d, em 1252-1253.

O Juízo Federal de 1a Instância colheu as provas de ambas as partes sobre os riscos da hoascapara a saúde e apossibilidade de seu desvio da igreja. O Governo apresentou provas de que o uso da hoasca, ou o DMT em geral, pode causar reações psicóticas, alterações cardíacas e interações medicamentosas adversas. A UDV rebateu citando estudos que comprovam a segurança do uso sacramental da hoasca e apresentando provas que minimizaram a probabilidade de riscos para a saúde invocados pelo Governo. No que diz respeito ao desvio, o Governo apontou um aumento geral no uso ilícito de alucinógenos e alegou interesse no uso ilegal de DMT e da hoasca em particular; A UDV enfatizou a escassez de qualquer mercado parahoasca, as quantidades relativamente pequenas da substância importadas pela igreja e a ausência de qualquer problema de desvio no passado.

O Juízo Federal de 1a Instância concluiu que a prova sobre os riscos para a saúde estava "em equilíbrio" e, de forma semelhante, a prova sobre o desvio foi "praticamente equilibrada". Id., em 1262, 1266. Em face de tal demonstração uniforme, o Tribunal argumentou que o Governo não havia conseguido demonstrar um interesse imperioso que justificasse o que reconheceu ser uma restrição significativa para o exercício religioso sincero da UDV. Id., em 1255. O Tribunal também rejeitou o interesse declarado no cumprimento da Convenção sobre Substâncias Psicotrópicas de 1971, sustentando que a Convenção não se aplica à hoasca. Id., em 1266-1269.

O Tribunal concedeu uma medida liminarproibindo o Governo de fazer cumprir a Lei de Substâncias Controladas no que diz respeito à importação e uso da hoasca pela UDV. A liminar exige que a igreja importe o chá em conformidade com as autorizações federais, para restringir o seu controle às autoridades da igreja e especialmente alertar os membros suscetíveis da UDV sobre os riscos da hoasca. Ver Medida Liminar,§§2, 5-12, 32-33, App. F to App. to Pet. for Cert.

Revista Publicum

Rio de Janeiro, v.4, n.1, 2018, p. 323-341

http://www.e-publicacoes.uerj.br/index.php/publicum

DOI: https://doi.org/10.12957/publicum.2018.33892 
249a, 250a-252a, 258a-259a. A decisão liminar prevê, também, que "se [o Governo] acreditar que existem provas de que a hoasca afeta negativamente a saúde dos membros da UDV", ou "que uma remessa de hoasca contenha níveis particularmente perigosos de DMT, [o Governo] pode solicitar ao Tribunal uma determinação judicialcélerepara saberse a prova justifica a suspensão ou a revogação da [autorização da UDV para usar hoasca]." Id., em257a, §29.

O Governo apelou da decisão liminar e uma das Câmaras do Tribunal Regional Federal da 10a Região manteve a decisão, Centro Espírita Beneficente União do Vegetal v. Ashcroft, 342 F. 3d 1170 (2003), como fez a maioria do Tribunal Pleno, 389 F. 3d 973 (2004). O recurso foi admitido na Suprema Corte [writ of certiorari]. 544 U.S. 973 (2005).

II

Embora as suas razões recursais contenham alguma discussão sobre o risco de danos e desvios do uso da hoascada UDV, o Governo não impugna a instrução processual realizada perante o Juízo Federal de 1a Instância ou a sua conclusão de que as provas apresentadas sobre essas questões foram equitativamente equilibradas. Em vez disso, o Governo sustenta que tal equilíbrio probatório é base insuficiente para a concessão de uma medidaliminar contra a aplicação da Lei de Substâncias Controladas. Reexaminamos as decisões judiciais de 1a Instância e sua decisão final de conceder uma medida liminar por abuso de discricionariedade. Ver McCreary County v. American Civil Liberties Union, 545 U.S. (2005) (slip op., em 19).

O Governo inicia invocando o princípio consolidado de que a parte que busca uma medida liminar tem o ônus de demonstrar a probabilidade de êxito no mérito. Ver, por exemplo, Mazurek v. Armstrong, 520 U.S. 968, 972 (1997) (per curiam); Doran v. Salem Inn, Inc., 422 U.S. 922, 931 (1975). O Governo argumenta que o Juízo Federal de 1ạ Instância perdeu de vista este princípio ao conceder a medida liminar com base em um mero empate probatório.

O Pleno do Tribunal Regional Federal, por maioria, rejeitou esse argumento, e nós também. Perante o Juízo Federal de 1ạ Instância, o Governo reconheceu o prima facie case da UDVnos termosda RFRA. Ver 282 F. Supp. 2d, em 1252 (a aplicação da Lei das Substâncias Controladas (1) restringiria substancialmente (2) uma sincera (3) prática religiosa). A prova que o Juízo Federal de 1ạ Instância considerou estar em equilíbrio relacionou-se com dois dos interesses relevantes alegados pelo Governo, que faziam parte da sua defesa indireta de mérito. Ver 42 U.S.C. §2000bb-1(b) ("O Governo pode restringir substancialmente o exercício da religião de uma pessoa somente se demonstrar que a aplicação do ônus à pessoa - (1) está na prossecução do interesse público imperioso..." (ênfase adicionada)); §2000bb-2(3) ("O termo 'demonstrar' significa cumprir os ônus de prosseguir com as provas e de convencer"). Por conseguinte, a UDV demonstrou efetivamente que o seu exercício sincero da religião estava 
sendo fortemente limitado, e o Governo falhou em demonstrar que a aplicação da restrição à UDV seria provavelmente justificada pelos interesses imperiosos. Ver 389 F. 3d, em 1009 (Seymour, J. concorda parcialmente) ("O equilíbrio está entre o real dano irreparável para o autor da ação e o dano potencial para o Governo, que nem sequer atingiu o nível de preponderância das provas").

O Governo argumenta que, embora suportasse o ônus de demonstrar um interesse imperioso como parte de sua defesa indireta no julgamento do mérito, a UDV deveria ter arcado com o ônus de refutar tais interesses na audiência sobre a decisão liminar. Este argumento é vedado pela nossa recente decisão no caso Ashcroft v. American Civil Liberties Union, 542 U.S. 656(2004). Em Ashcroft, afirmamos que a concessão de uma medida liminarem um caso onde o Governo falhou em demonstrar a probabilidade de êxito com base no teste de interesse imperioso. Concluímos que "como o Governo tem o ônus da prova sobre a questão final da constitucionalidade [da Lei impugnada], os recorridos [requerentes] devem ser considerados prováveis vencedores, a menos que o Governo demonstre que as alternativas menos restritivas propostas pelos réus sejam menos eficazes do que [o cumprimento da Lei]. "Id., em666. Essa lógica se estende para este caso; aqui o Governo falhou no primeiro requisito do teste de interesse imperioso, e não empregou o meio menos restritivo, mas isso não faz diferença. A questão é que o ônus em sede de liminar segue o ônus do julgamento.

O Governo tenta limitar a regra expostano caso Ashcroft às restrições baseadas no conteúdo da expressão, mas a distinção é ineficaz. O fato de o caso Ashcroftter envolvido tal restrição foi a razão pela qual o Governo deteve o ônus da prova no julgamento, conforme o disposto na Primeira Emenda, ver Id., em 665, mas de modo algum afetou a avaliação da Corte sobre as consequências de ter esse ônus para fins de concessão de medida liminar. Aqui, o ônus é indubitavelmente atribuído ao Governo pela RFRA e não pela Primeira Emenda, ver 42 U.S.C. $\S \S 2000$ bb-1(b), 2000bb-2(3), mas as consequências são as mesmas. A decisão expressa do Congresso de estabelecerem lei o teste de interesse imperioso indica que as impugnações da RFRA devem ser julgadas da mesma forma que os pedidos constitucionalmente exigidos pelo teste, inclusive em sede de liminar.

III

A segunda linha de argumentaçãodo Governo baseia-se na própria Lei das Substâncias Controladas. O Governo afirma que a descrição da Lei sobre as substâncias da Lista I como tendo "um alto potencial de abuso", "nenhum uso médico atualmente aceito nos Estados Unidos" e a "falta de segurança aceita para uso... sob supervisão médica", 21 U.S.C. §812 (b)(1), por si só, impossibilita qualquer consideração de exceções individualizadas, como a requerida pela UDV. O

Revista Publicum 
Governo prossegue alegando que o regime jurídico estabelecido pela Lei - um sistema "fechado" que proíbe qualquer uso de substâncias controladas, exceto quando autorizado pela própria Lei, ver Gonzales v. Raich, 545 US (2005) (slipop., em 10) - "não pode funcionar com o necessário rigor e abrangência se estiver sujeito àsexceções judiciais." Razões dos Recorrentes [Brief for Petitioners] 18. De acordo com o Governo, não haveria como acolher exceções religiosas uma vez reconhecidas, e "o público irá interpretar mal" tais exceções, como um sinal de que a substância em questão não é prejudicial, no fim das contas. Id., em 23. Sob o ponto de vista do Governo, não há necessidade de avaliar as particularidades do uso pela UDV ou sopesar o impacto de uma isenção para esse uso específico, porque a Lei de Substâncias Controladas cumpre uma finalidade relevante e simplesmente não admite exceções.

A

A RFRA, e seu teste de escrutínio rigoroso, contemplam uma investigação mais centrada do que a abordagem categórica do Governo. A RFRA exige que o Governo demonstre que o teste de interesse imperioso é satisfeito através da aplicação da lei impugnada "para a pessoa" determinado requerente cujo exercício sincero da religião está sendo substancialmente restringido. 42 U.S.C. $\$ 2000 b b-1(b)$. A RFRA adotou expressamente o teste de interesse imperioso, "conforme demonstrado em Sherbert v. Verner, 374 U.S. 398 (1963) e em Wisconsin v. Yoder, 406 U.S. 205 (1972)." 42 U.S.C. §2000bb(b)(1). Em cada um desses casos, esta Corte olhou além dos interesses amplamente formulados, justificando a aplicabilidade geral das diretrizes governamentais e escrutinou o prejuízo declarado da concessão de isenções específicas a determinados requerentes religiosos. No caso Yoder, por exemplo, permitimos uma isenção para crianças Amish de uma lei de frequência escolar obrigatória. Reconhecemos que o Estado tinha um interesse "importantíssimo" na educação, mas sustentamos que "apesar da validade admitida na generalidade dos casos, devemos analisar atentamente os interesses que o Estado procura promover... e o impedimento para aqueles objetivos que resultariam do reconhecimento da isenção requerida pelos Amish". 406 U.S., em 213, 221 (ênfase adicionada). A Corte explicou que o Estado precisava "demonstrar com mais particularidade como o seu interesse reconhecidamente forte... seria prejudicado pela concessão de uma isenção para os Amish." Id., em 236 (ênfase adicionada).

No caso Sherbert, a Corte manteve um determinado pedido para isenção religiosa de lei estadual que recusava o seguro-desemprego para aqueles que não trabalhavam aos sábados, mas explicou que não estava declarando um direito constitucional de seguro-desemprego para "todas as pessoas cujas convicções religiosas são a causa de seu desemprego." 374 U.S., em 410 (ênfase adicionada). O Tribunal distinguiu o caso "em que as conviç̧ões religiosas de um 
funcionário servem para torná-lo um membro não-produtivo da sociedade". Ibid.; ver também Smith, 494 U.S., em 899 (O'Connor, J., votando com o relator) (o exame rigoroso "pelo menos requer uma determinação caso a caso da questão, sensível aos fatos de cada reivindicação particular"). Fora do âmbito de livre exercício religioso, o Tribunal observou que "o contexto importa" na aplicação do teste de interesse imperioso, Grutter v. Bollinger, 539 US 306, 327 (2003), e enfatizou que "o escrutínio rigoroso realmente leva em conta as 'diferenças relevantes' - com efeito, esse é seu propósito fundamental", Adar and Constructors, Inc. v. Peña, 515 U.S. 200, 228(1995).

Sob a investigação mais centrada exigida pela RFRA e pelo teste de interesse imperioso, a mera invocação do Governo das características gerais das substâncias da Lista I, conforme estabelecido na Lei de Substâncias Controladas, não pode prevalecer. É verdade, certamente, que as substâncias da Lista I, como o DMT, são excepcionalmente perigosas. Ver, por exemplo, Toubyv. Estados Unidos, 500 U.S. 160, 162 (1991). No entanto, não há indícios de que o Congresso, ao classificar o DMT, tenha considerado os prejuízos causados pelo uso particular em questão - o uso circunscrito e sacramental dahoasca pela UDV. A questão dos prejuízos causados pelo uso sacramental dahoasca pela UDV foi discutida abaixo. Antes que o Juízo Federal de 1ạ Instância considerasse que o Governo não havia suportado o ônus de demonstrar um interesse imperioso na prevenção de tais danos, o Tribunal observou que não poderia "ignorar que o ramo legislativo do Governo eleito inseriu materiais contendo DMT na Lista I da Lei, refletindo as determinações de que as substâncias contendo DMT têm "um alto potencial de abuso", "nenhum uso médico atualmente aceito em tratamentos nos Estados Unidos", e que "há falta de segurança para o uso [do DMT] sob supervisão médica."282 F. Supp. 2d, em 1254. Mas a determinação do Congresso de que o DMT deve estarrelacionado na Lista I simplesmente não fornece uma resposta categórica que desobrigue o Governo de suportar oônus imposto pela RFRA.

Esta conclusão é reforçada pela própria Lei de Substâncias Controladas. A Lei contém uma disposição que autoriza o Procurador-Geral a "dispensar o requisito de registro de certos fabricantes, distribuidores ou prescritor esse ele o considerar compatível com a saúde pública e segurança". 21 U.S.C. §822(d). O fato de a própria Lei considerar que a isenção de certas pessoas de seus requisitos seria "compatível com a saúde e a segurança públicas" indica que as determinações do Congresso em relação às substâncias da Lista I não devem conter o peso determinante, para fins da RFRA, que o Governo atribuiria a elas. 
E, de fato, foi feita uma exceção à proibição da Lista I para uso religioso. Nos últimos 35 anos, tem havido uma exceção legal para o uso do peiote - uma substância da Lista I - pela Igreja Nativa Americana. Ver 21 CFR $§ 1307.31$ (2005). Em 1994, o Congresso estendeu essa exceçãoa todos os membros das tribos indígenas reconhecidas. Ver 42 U.S.C. §1996a (b) (1). Tudo o que o Governo diz sobre o DMT nahoasca - que, como substância da Lista I, o Congresso tenha determinado que "tem um alto potencial de abuso", "não tem uso médico atualmente aceito" e tem "uma falta de segurança aceita para uso... sob supervisão médica", 21 U.S.C. §812(b)(1) -se aplica em igual medida à mescalina no peiote, embora tanto o Executivo quanto o próprio Congresso tenham instituído uma exceção na Lei de Substâncias Controladas para o uso religioso do peiote pelos índios americanos. Se tal uso é permitido em face das determinações do Congresso no §812(b)(1) para centenas de milhares de Nativos americanos praticarem a sua fé, é difícil ver como essas mesmas determinações, por si só, possam impedir qualquer consideração de uma exceção similar para os 130 ou mais membros americanos da UDV que desejam praticar a sua fé. Ver Igreja de Lukumi Babalu Aye, Inc. v. Hialeah, 508 US 520, 547 (1993) ("Está assentado em nossa jurisprudência sobre o escrutínio rigoroso que "uma lei não pode ser considerada como protetora de um interesse 'da mais alta ordem'... quando deixa um dano substancial a esse supostamente permitido interesse vital" (citando Florida Star v.B. J. F., 491 U.S. 524, 541-542 (1989) (SCALIA, J., concordando em parte e acompanhando o relator)).

O Governo responde que há uma "relação singular" entre os Estados Unidos e as Tribos, Razões dos Recorrentes 27; ver Morton v. Mancari, 417 U.S. 535 (1974), mas nunca explica sobre como essa relação "singular" justifica sobrepor-se às mesmas determinações do Congresso sobre as quais o Governo se baseia para resistir a qualquer exceção para o uso religioso da hoasca pela UDV. Em outras palavras, se qualquer substância da Lista I é, de fato, sempre altamente perigosa em qualquer quantidade, independentemente de comoé utilizada, o que dizer da relação singular com as Tribos para justificara permissão do uso do peiote? Nada sobre o status político singular com as Tribos torna seus membros imunes aos riscos à saúde que o Governo afirma haver no uso de uma substância da Lista I, nem isola a substância da Lista I que as Tribos usam em seu exercício religioso do alegado risco de desvio.

O Governo argumenta que a existência de uma isenção do Congresso para o uso do peiote não indica que a Lei de Substâncias Controladas seja passível de exceções criadas judicialmente. A RFRA, no entanto, claramente contempla que os tribunais reconheceriam exceções - é assim que a lei funciona. Ver 42 U.S.C. §2000bb-1(c) ("Uma pessoa cujo exercício religioso tenha sido restringido, em violação a este artigo, pode alegar essa violação em uma ação ou em defesa de um processo judicial e obter tutela adequada contra um governo"). A função do Congresso na isenção do uso do peiote - e a do Executivo, ver 21 CFR $\$ 1307.31$ (2005) - confirma que as 
determinações da Lei de Substâncias Controladas não impedem completamente exceções; a RFRA deixa claro que é dever dos tribunais considerarem se as exceções são necessárias sob o teste estabelecido pelo Congresso.

\section{C}

A bem estabelecida exceção do uso do peiote também enfraquece fatalmente a alegação mais ampla do Governo de que a Lei das Substâncias Controladas estabelece um sistema regulatório fechado que não admite nenhuma exceção prevista na RFRA. O Governo argumenta que a efetividade da Lei das Substâncias Controladas será "necessariamente reduzida" se a lei não for aplicada uniformemente, sem levar em conta as restrições ao exercício religioso. Razões dos Recorrentes 18. A exceção do peiote, no entanto, está em vigor desde a edição da Lei de Substâncias Controladas e não há provas de que tenha "reduzido" a capacidade do Governo de impor a proibição do uso de peiote por não-índios.

O Governo aponta para alguns casos pré-Smith, que se baseiam na necessidade de uniformidade na rejeição dospedidos de isenções religiosas com base na Cláusula de Livre Exercício Religioso, ver Razões dos Recorrentes 16, mas esses casos nos parecem bem diferentes da presente demanda. Tais casos não abrangeram a noção de que um interesse geral na uniformidade justificava uma restrição substancial sobre o exercício religioso; em vez disso, examinaram a necessidade alegada e explicaram porque as exceções negadas não poderiam ser acolhidas. No caso Estados Unidos v. Lee, 455 US 252 (1982), por exemplo, a Corte rejeitou um pedido de exceção à obrigação de pagar os impostos da Seguridade Social, observando que "a participação compulsória é indispensável para a vitalidade fiscal do sistema de seguridade social" e que o "sistema fiscal não poderia funcionar se as denominações tivessem permissão para contestar o sistema tributário porque os pagamentos de impostos foram empregados de maneira que violava sua crença religiosa". Id., em 258, 260. Ver também Hernandez v. Comissário, 490 US 680, 700 (1989) (o mesmo). No caso Braunfeldv. Brown, 366 US 599 (1961) (voto majoritário), o Tribunal negou um pedido de exceção às leis de fechamentoaos domingos, em parte porque permitir tais exceções "poderia facilmenteproporcionar [aos requerentes] uma vantagem econômica sobre seus concorrentes que devem permanecer fechados naquele dia. "Id., em 608609. Aideia central de um "dia de descanso comum para todos os trabalhadores" teria sido frustrada pelas exceções. Ver Sherbert, 374U.S., em 408 (discutindo Braunfeld). Esses casos mostram que o Governo pode demonstrar um interesse imperioso na aplicação uniforme de um determinado programa, oferecendo provas de que a concessão das exceções religiosas requeridas comprometeria seriamente sua capacidade de administrar o programa.

Revista Publicum

Rio de Janeiro, v.4, n.1, 2018, p. 323-341

http://www.e-publicacoes.uerj.br/index.php/publicum

DOI: https://doi.org/10.12957/publicum.2018.33892 
Aqui, o argumento do Governo para a uniformidade é diferente; não se baseia no programa institucional em questão como nas preocupações de "piso escorregadio", que poderiam ser invocadas em resposta a qualquer pedido de exceção com base na RFRA a uma lei de aplicabilidade geral. $\mathrm{O}$ argumento do Governo ecoa a réplica clássica de burocratas ao longo da história: Se eu abrir uma exceção para você, eu vou ter que abrir uma para todos, então não há exceções. Mas a RFRA opera exigindoa consideração, sob o teste de interesse imperioso, de exceções para "a[s] norma[s] de aplicabilidade geral". 42 U.S.C. §2000bb-1(a). O Congresso determinou que o teste previsto na lei "é um teste viável para a encontrar equilíbrios razoáveis entre liberdade religiosa e os mais importantes interesses públicos concorrentes". §200bb(a)(5). Esta determinação encontra respaldo em nossos casos; no caso Sherbert, por exemplo, rejeitamos um argumento de piso escorregadio semelhante ao apresentado neste caso, descartando como "não mais do que uma possibilidade" a especulação do Estado "de que o ajuizamento de ações fraudulentas por requerentes inescrupulosos, fingindo objeções religiosas para o trabalho de sábado" drenaria o fundo de benefícios de desemprego. 374 U.S., em 407.

Reafirmamos justamente na sessão anterior a viabilidade de uma consideração caso a caso de isenções religiosas às normas de aplicabilidade geral. No caso Cutter v. Wilkinson, 544 US __ (2005), decidimos que a Lei do Uso Religioso da Terra e Pessoas Institucionalizadas [Religious Land Use and Institutionalized Persons Act] de 2000, que permite que os prisioneiros federais e estaduais busquem instalações religiosas de acordo com o mesmo padrão estabelecido na RFRA, não viola a Establishment Clause ${ }^{6}$. Não tivemos "nenhum motivo para acreditar" que o teste de interesse imperioso "não seria aplicado de maneira adequadamente equilibrada" para determinados pedidos de isenções na medida em que surgissem. Id., em__ (slip op., em 12). Nada em nossa decisão sugeriu que os tribunais não estavam à altura da tarefa.

Não duvidamos que possam existir situações em que uma necessidade de uniformidade impeça o reconhecimento de exceções às leis de aplicabilidade geralao abrigo da RFRA. Mas teria sido surpreendente achar que este fosse tal caso, dado o longo período de duraçãoda isenção da Lei de Substâncias Controlados para uso religioso do peiote e o fato de que a verdadeira razão pela qual o Congresso promulgou a RFRA foi responder a uma decisão que negou uma reivindicação do direito do uso sacramental de uma substância controlada. Ver 42 U.S.C. $\S 2000 b b(a)(4)$. E, de fato, o Governo não ofereceu provas que demonstrassem que a concessão de uma isenção à UDV causaria um tipo de prejuízo administrativo considerado como um interesse imperioso, conforme demonstrado em Lee, Hernandez e Braunfeld. O Governo falhou em convencer o Juízo Federal de 1a Instância na audiência preliminar de que as preocupações

${ }^{6}$ Dispositivo constitucional norte-americano que proíbe o Congresso de estabelecer uma religião oficial ou dar preferência a uma determinada religião. [N. do T.]

Revista Publicum

Rio de Janeiro, v.4, n.1, 2018, p. 323-341

http://www.e-publicacoes.uerj.br/index.php/publicum

DOI: https://doi.org/10.12957/publicum.2018.33892 
com a saúde ou com o desvio constituem um interesse imperioso na proibição do uso sacramental da hoasca pela UDV. Ele não pode compensar essa falha agora sob o ousado argumento de que não pode haver, de maneira nenhuma, exceções à Lei de Substâncias Controladas com base na Lei de Restauração da Liberdade Religiosa. Ver transcrição da sustentação oral 17 (declaração do Procurador-Geral adjuntoque essa exceção não poderia ser feita até mesmo para o uso "rigorosamente controlado" de "uma gota" da substância "uma vez por ano").

\section{IV}

Perante o Juízo Federal de 1ạ Instância, o Governo também afirmou um interesse no cumprimento da Convenção das Nações Unidas sobre Substâncias Psicotrópicas de 21 de fevereiro de 1971, [1979-1980], 32 U.S.T. 543, T.I.A.S. n. 9725. A Convenção, assinada pelos Estados Unidos e implementada pela Lei de Substâncias Controladas, insta os signatários que proíbam o uso de alucinógenos, incluindo o DMT. O Governo argumenta que tem um interesse imperioso no cumprimento de suas obrigações internacionais em conformidade com a Convenção.

O Juízo Federal de 1a Instância rejeitou esse interesse porque considerou que a Convenção não abrange a hoasca. O juízo baseou-se no comentário oficial da Convenção, que observa que "a Lista I [da Convenção] não relaciona... substâncias alucinógenas naturais" e que "as plantas, como tais, não estão e provavelmente não estarão relacionados na Lista I, mas apenas alguns produtos obtidos das plantas." Comentário das Nações Unidas sobre a Convenção sobre Substâncias Psicotrópicas 387, 385 (1976). O juízo ponderou que a hoasca, assim como as plantas das quais o chá é feito, é suficientemente diferente do DMT em si para ser abrangida pelo tratado. Ver 282 F. Supp. 2d, em 1266-1269.

Não concordamos. A Convenção estabelece que "um preparado está sujeito às mesmas medidas de controle que a substância psicotrópica nele contida" e define "preparado" como "qualquer solução ou mistura, em qualquer estado físico, que contenha uma ou mais substâncias psicotrópicas". Ver 32 U.S.T., em 546, art. 1ㅇ⒡(i);id., em551, art. 3o. A hoasca é uma "solução ou mistura" que contém DMT; o fato de que é produzida pelo simples processo de decocção das plantas, ao invés de algum método mais avançado, não a altera. $O$ alcance que o comentário sugerede que a Convenção não abrange as plantas não é relevante - a UDV procura importar e usar um chá feito a partir de plantas, não as próprias plantas, e o chá é qualificado simplesmente como um "preparado", nos termos da Convenção.

Revista Publicum

Rio de Janeiro, v.4, n.1, 2018, p. 323-341

http://www.e-publicacoes.uerj.br/index.php/publicum

DOI: https://doi.org/10.12957/publicum.2018.33892 
O fato de que a hoascas já estejam abrangidas pela Convenção, no entanto, não significa automaticamente que o Governo tenha demonstrado um interesse imperioso na aplicação da Lei de Substâncias Controladas, que implementa a Convenção, quanto ao uso sacramental do chá pela UDV. Nesta fase, basta observar que o Governo nem sequer apresentou provas que versassem sobre as consequências internacionais da concessão de uma isenção para a UDV. 0 Governo simplesmente exibiu dois depoimentos juramentados de funcionários do Departamento de Estado atestando a importância geral de honrar as obrigações internacionais e manter a posição de liderança dos Estados Unidos na guerra internacional contra as drogas. Ver Declaração de Gary T. Sheridan (24 de janeiro de 2001), App. G to App. to Pet. for Cert.261a; Declaração de Robert E. Dalton (24 de janeiro de 2001), App. H, id., em265a. Não duvidamos da validade desses interesses, da mesma maneira que não duvidamos do interesse geral em promover a saúde e a segurança públicas através da aplicação da Lei de Substâncias Controladas, mas nos termos da Lei de Restauração da Liberdade Religiosa, a invocação de tais interesses gerais, por si só, não é suficiente. $^{7}$

O Governo invoca repetidamente as decisõe se os propósitos do Congresso que ensejaram a Lei de Substâncias Controladas, mas o Congresso também teve um motivo para promulgar a Lei de Restauração da Liberdade Religiosa. O Congresso reconheceu que as “leis 'neutras' em relação à religião podem restringir o exercício religioso tão seguramente quanto as leis que pretendem interferir no exercício religioso" e estabeleceu "o teste de interesse imperioso" como meio para que os tribunais "encontrem equilíbrios razoáveis entre a liberdade religiosa e os mais importantes interesses públicos concorrentes". 42 U.S.C. $\S 2000 b b(a)(2),(5)$.

Não temos motivo para fingir que a função atribuída pelo Congresso aos tribunais no âmbito da RFRA é fácil. Com efeito, asdiversas dificuldades aqui destacadas pelo Governo forammencionadas por esta Corte ao decidir que a abordagem estipulada pelo Congresso no âmbito da RFRA não foi necessária como uma questão de direito constitucional, nos termos da Cláusula de Livre Exercício Religioso. Ver Smith, 494 U.S., em 885-890. Mas o Congresso determinou que os tribunais devem encontrar equilíbrios razoáveis, de acordo com um teste de interesse imperioso que exige que o Governo trate da determinada prática em questão. Aplicando esse teste, concluímos que os Tribunais a quo não erraram ao decidir que o Governo

\footnotetext{
7 À luz do exposto, não acolhemos o argumento da UDV, segundo o qual o art. 22, §5o, da Convenção deve ser lido para acolher isenções previstas nas leis nacionais, como a RFRA.

Revista Publicum

Rio de Janeiro, v.4, n.1, 2018, p. 323-341

http://www.e-publicacoes.uerj.br/index.php/publicum

DOI: https://doi.org/10.12957/publicum.2018.33892
} 
não demonstrou, em sede de liminar, um interesse imperioso em proibir o uso sacramental da hoasca pela UDV.

A decisão do Tribunal Regional Federal da 10ạ Região é confirmada e os autos são remetidos para novos procedimentos, nos termos do presente acórdão.

Assim é ordenado.

O Ministro ALITO não participou da discussão e da decisão deste caso. 